\title{
Automatização de Acesso de Veículos à Estacionamentos
}

\author{
Tatiele Martins Razera \\ Faculdade de Tecnologia SENAI \\ Joinville \\ Brasil \\ tatiele.razera@edu.sc.senai.br
}

\author{
Ademir Camillo Junior \\ Faculdade de Tecnologia SENAI \\ Joinville \\ Brasil \\ ademir.camillo@edu.sc.senai.br
}

\author{
Eduardo Henrique Mussi \\ Faculdade SENAI \\ Santa Catarina \\ Brasil \\ eduardoh.mussi@gmail.com
}

\author{
Samoel Laureano Angélica \\ Faculdade SENAI \\ Santa Catarina \\ Brasil \\ samoellaureano@gmail.com
}

\author{
Felipe Correia Schulz \\ Faculdade de Tecnologia SENAI \\ Joinville \\ Brasil \\ felipe_schulz@estudante.sc.senai.br
}

\begin{abstract}
Technological advancement and the growing number of vehicles enable innovative solutions. The mission of this work is to bring up a computational response capable of detecting and recognizing automotive license plates, in order to control access in private areas, as well as the storage and availability of information generated from this solution. For this purpose, the OpenCv library was used to process the images. As a result, $43,3 \%$ of correct answers were obtained in the recognition of the detected plaques.
\end{abstract}

\section{KEYWORDS}

Automatização, Veículos, Placas, Processamento de imagens, OCR.

\section{INTRODUÇÃo}

0 avanço da tecnologia, tem ocasionado uma revolução em âmbito mundial, promovendo o aperfeiçoamento e o acesso rápido à informação.

0 desenvolvimento do reconhecimento de caracteres a partir de imagens, auxiliou em diversos setores, entre eles o controle de acesso de veículos em estacionamentos e áreas privativas.

Devido ao crescente número de veículos transitando pelas cidades, tornou-se cada vez mais necessário o controle destes de forma a garantir a segurança dos mesmos [1].

Em muitos casos, estacionamentos passam por alguns desafios, como a falta de segurança e controle das informações, pois muitas vezes possuem somente controle manual por funcionários, que em muitos casos realizam anotações dos dados do veículo e os horários de entrada e saída.

Diante dessa situação, identificou-se a possibilidade de automatizar alguns processos, como o gerenciamento dos acessos, o registro e armazenamento das informações do cliente e veículos que utilizam o serviço, através do reconhecimento por imagem e liberação do acesso.

\section{TRABALHOS RELACIONADOS}

O trabalho do autor [2], traz como objetivo, o uso de fases de processamento de imagem para a identificação de placas automotivas no intuito de reconhecer os veículos que trafegam em um determinado local, atendendo assim às necessidades de fiscalização para a melhor manutenção da ordem e até mesmo da segurança.

0 trabalho de [3], tem por objetivo apresentar diversas técnicas para o reconhecimento de caracteres. 0 autor demonstra a detecção de placas de identificação automotivas e os passos para a sua interpretação. São apresentadas etapas para tratamento das imagens, como a detecção das áreas de interesse, aquisição de segmentos significativos e interpretação dos caracteres.

\section{METODOLOGIA}

A captura automatizada da placa será realizada na entrada do estabelecimento, em seguida realiza-se o processamento e os caracteres são enviados para o sistema a fim de realizar o Check-in ou Check-out.

O sistema foi desenvolvido em JAVA 8, utilizando o framework JPA (Java Persistence API), com Hibernate, HTML5, CSS3 e JavaScript. As rotinas para reconhecimento e 
XII Computer on the Beach,

transformação da placa em caracteres foram desenvolvidas utilizando OpenCV e PyTesseract OCR.

A detecção da placa é iniciada por meio da segmentação da área de interesse, em seguida são realizadas etapas de transformação em escala de cinza; limiarização e remoção de ruídos com filtro Gaussiano, para estas etapas utilizou-se a biblioteca Opencv [2] em conjunto com o método PyTesseract OCR, o qual realiza a conversão dos caracteres em texto.

\section{RESULTADOS E DISCUSSÕES}

A primeira etapa do reconhecimento das placas consiste em enquadrá-la corretamente, para então capturá-la, de forma a reconhecer os caracteres com maior precisão.

Os resultados obtidos podem ser observados na Tabela 1, a qual apresenta respectivamente, a quantidade de placas analisadas, o percentual para o processamento da imagem em cada uma das etapas e a quantidade de caracteres convertidos para texto de forma correta.

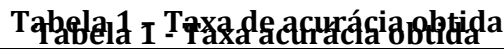

\begin{tabular}{ccc}
\hline & Quantidade & Percentual \\
\hline Placa Análisada & 32 & \\
\hline Enquadramento & 16 & $50 \%$ \\
\hline Conversão total da placa & 8 & $25 \%$ \\
\hline Caractere Convertido & 97 & $43,3 \%$ \\
\hline
\end{tabular}

Conforme os resultados apresentados, entre as 32 placas analisadas, o enquadramento ocorreu corretamente em 16 delas, com um percentual de 50\%. Obteve-se 8 conversões totais das placas, o qual resultou em $25 \%$, do total de placas. Analisando o processo de detecção e conversão pelo número de caracteres, foi possível obter como resultado a conversão de 97 caracteres, visto que cada placa possui 7 caracteres, onde a quantidade total para as placas analisadas é de 224, representando 43,3\% de letras e números convertidos para texto.

\section{CONSIDERAÇÕES FINAIS}

Como pode ser observado nos trabalhos relacionados, assim como em simulações realizadas, o reconhecimento das imagens depende de diversos fatores, como luminosidade, resolução da imagem, ângulo de captura, posicionamento,entre outros.

Como possibilidade de melhoria recomenda-se a busca por outros filtros voltados ao processamento da imagem e reconhecimento de borda, para que seja obtido um maior percentual de enquadramento das placas capturadas. Também pode-se utilizar outras técnicas de pré-processamento, como por exemplo Canny Edge,ou outras técnicas que venham a contribuir para melhor detecção dos caracteres e segmentação da placa.

Pode-se citar também o desenvolvimento de uma rotina para detecção e conversão individual dos caracteres.

\section{REFERÊNCIAS}

[1] Aster, 2015, Novidades tecnológicas do setor de segurança, Disponivel em: aster.com.br/blog/seguranca-patrimonial /novidades- tecnologicas-dosetor-de-seguranca/, [Online: acessado 17/11/2020].

[2] V. Bergoli, L. Antonio, A. Nilceu Marana. 2010. Reconhecimento Automático de Placas de Veículos. VI Workshop de Visão Computacional.( Jul. 2010 ), Disponível em: iris.sel.eesc.usp.br/ wvc /anais_WVC2010/artigos/poster/72819.pdf, [Online: acessado 20/07/2020].

[3] N. Hudson. 2018. Estudo de técnicas para reconhecimento ótico de caracteres e seu uso para detecção de placas de identificação automotivas brasileiras. Revista de Engenharia e Tecnologia. V. 10, No. 3, (Dez. 2018), Disponível em: revistas2.uepg.br/index.php /ret/article/download/11993/209209210197/, [Online: acessado $23 / 07 / 2020]$. 